\title{
Lip Prints and Gender Identification
}

\author{
Makesh Raj LS ${ }^{1}$, Sai Krishna $\mathrm{P}^{2}$, Shankar KA ${ }^{2}$, Jude J ${ }^{3}$, \\ Jai Santhosh Manikandan $\mathrm{V}^{3}$, Priyadarshini $\mathrm{T}^{4}$ \\ ${ }^{1}$ (Reader, Department of oral pathology, Tagore Dental College and Hospital, India) \\ ${ }_{2}^{2}$ (Professor, Department of oral pathology, Tagore Dental College and Hospital, India) \\ ${ }^{3}$ (Senior Lecturer, Department of oral pathology, Tagore Dental College and Hospital, India) \\ ${ }^{4}$ (Lecturer, Department of Periodontics, Tagore Dental College and Hospital, India)
}

\begin{abstract}
Lip prints are wrinkles and grooves present in the transition zone of human lip. The study of lip print is referred to as cheiloscopy and it is unique to every individual. They do not change during their entire life. The purpose of this study is to find out most common lip print pattern and to assess their efficacy in sex determination. In this study, each individual had unique lip print pattern. Type I (vertical) was the predominant pattern in both males and females. There is statistically significant difference between gender and type of upper lip print pattern, but there is no correlation regarding lower lip pattern contradictory to many earlier studies. Hence, lip prints can be used as tool for identification of an individual and gender identification.
\end{abstract}

Keywords: cheiloscopy, Forensic odontology, gender identification, lip prints, sex determination

\section{Introduction}

Lip prints are normal lines and fissures in the form of wrinkles and grooves present in the transitional zone of human lip. Suzuki and Tsuchihashi (1970) coined the term "sulci labiorum" and the lip prints consisting of these grooves as "Figura linearum labiorum rubrorum". The study of lip print is referred to as cheiloscopy. Lip prints are unique to every individual just like the fingerprints.

Fischer (1902) was the first anthropologist to describe in detail about lip prints. However, it was Edmond Locard (1932) who recommended the use of lip prints in personal identification and criminalization. Synder (1950) identified that lip grooves are individually distinct, similar to that of ridge characteristics seen in finger prints. Mc Donell (1972) identified that lip prints were only distinguish factors between two identical twins. (1)

Lip print patterns are identified as early as the sixth week of intrauterine life. They are unique to an individual and do not change during their entire life. (3) It has been verified that lip prints recover after undergoing alterations like minor trauma, inflammation and diseases like herpes. The form of the furrows does not vary due to environmental factors like weather and temperature. $(4,5)$

Latent, visible or both forms of lip prints can be identified in a crime scene. The latent lip prints can be developed by using a wide variety of chemicals, ranging from conventional powders to lysochrome dyes. (6)

This study was conducted to find out most common lip print pattern and to assess their efficacy in sex determination among south Indian population.

\section{Materials And Method}

Total sample size of 100 individuals comprising of 46 males and 54 females in the age group of 18 to 25 years were included in the study. Informed consents were obtained from the subjects. Patients with congenital abnormalities of lip, inflammation and trauma were excluded from the study.

A dark-colored lipstick was applied with a single stroke and the subjects were asked to rub both the lips to spread the lipstick. After 2 min of application, glued portion of cellophane tape which is slightly more than the breadth of subject's lips is placed over the transitional zone. Lip prints were obtained in the normal rest position by dabbing in the centre first and then proceeding with care towards the corner of the lips. The cellophane strip is then stuck to the white bond paper for a permanent record and then visualized through a magnifying glass.

The middle part of the upper and lower lip print, about $10 \mathrm{~mm}$ alone was considered for the study because lateral part of the lip print possess high risk of destruction. The lip prints were examined and classified in accordance with the method proposed by Suzuki and Tsuchihashi et al. (Table 1)

\section{Results}

From our study, every individual had different lip print pattern and they were unique to each person. Among both upper and lower lip prints, type I (vertical) was the predominant pattern in both males and females. Statistically significant difference is observed between gender and overall type of lip print pattern. (Table 2) 
In lower lip, type I (vertical) was the predominant pattern for both males and females $(54.3 \%$ and $51.9 \%$ ). In upper lip, type II pattern (branched) appear to be common in males (45.7\%) and type IV pattern (reticular) in females $(40.7 \%)$. Fisher exact test reveals that there is a significant difference between genders and the upper lip pattern only. (Table 3)

\section{Discussion}

Stability, patterns among races and gender are the common studies done using lip prints. Research has shown that lip prints are unique to an individual and constant over time. It has been found that lip print patterns are also inherited. Just like fingerprints, lip prints have a specific pattern of fissures. Hence lip prints are very useful in forensic investigations and personal identification. A study found that there were no postmortem changes in anthropometric measurements of the lip region before and after fixation. (7)

Most of the crime scene investigators ignore lip prints. Lip prints can be visible or latent in a crime scene. (8) The oily, moist secretions from sebaceous and salivary glands moisturize the lip which enables the formation of a latent lip print. Various physical evidences at the crime scene such as photographs, letters, glass, window panes, cutlery, cigarette butts, clothing, and even biological materials such as skin may bear latent, visible, or both types of lip prints.(9)

During 1985-87, cheiloscopy techniques were used in 85 cases including 65 cases of burglary, 15 cases of homicide and five cases of assault. In 34 cases, the identification was positive which means that cheiloscopic technique is equal in value with other forensic techniques. (10)

Several methods have been proposed to classify lip print pattern, like simple versus compound branching patterns (Santos, 1967), distinct branching patterns (Suzuki and Tsuchihashi, 1970), formulas derived from each specific groove (Renaud, 1973) and individual features of line pattern (Kasprzak). None of the above mentioned classification has been universally accepted.

Various studies have been conducted to detect the predominant lip pattern (table 3). In the present study, type I (vertical) was the predominant pattern in both males and females. Similar results were obtained in studies done by Sandhu et al., Koneru A et al., Singh J et al., Vahanwalla and Parekh. On contrary, Sivapathasundaram et al., and Saraswati et al., showed that type III was predominant pattern, while Varghese et al., found Type IV as predominant pattern in Kerala population. $(1,10,11,12,13)$

In our study, type I (vertical) was the predominant pattern in lower lip for both males and females. Similar results were obtained by Koneru A et al., Dwivedi N et al and Peeran SW et al. While Venkatesh et al., in his study showed contrary results with type V being more predominant. $(10,14,15)$

In upper lip, type II pattern (branched) appear to be the common in males (45.7\%) and type IV pattern (reticular) in females $(40.7 \%)$. Most of the studies showed type $\mathrm{I}$ is the predominant pattern. But, in study done by Dwivedi $\mathrm{N}$ et al., type II, III is the common pattern.

Variation in patterns between upper and lower lips may be attributed to the following factors: a) mode of development; b) lip muscles relaxed to produce a particular pattern; c) lip moisture difference; and d) continuity of lips with adjacent skin lines.(10)

Various studies have utilized quadrant based recording, while few studies have utilized only middle part of both lips. Our findings are similar to many studies in earlier literature and contradictory to few. The reason behind these variations may be due to

1. Lack of uniform procedure in obtaining lip prints.

2. Lack of universal classification in interpreting the lip prints

Hence, as of now lip prints can be used for fool proof identification of an individual since it is unique; but it is questionable to use it as a tool for gender identification.

\section{Conclusion}

Lip prints can be used as an additional tool for personal identification. Although, lip print analysis has been used in court of law for certain cases, more research has to be conducted with regard to its uniformity in recording and interpretation.

\section{References}

[1]. Saraswathi TR, Mishra G and Ranganathan K, Study of lip prints, Journal of Forensic Dental Sciences, 1(1), $2009,28-31$.

[2]. Sharma P, Saxena S and Rathod V, Cheiloscopy: The study of lip prints in sex identification, Journal of Forensic Dental Sciences, 1(1), 2009, 24-27.

[3]. Venkatesh R and David MP, Cheiloscopy: An aid for personal identification, Journal of Forensic Dental Sciences, 3(2), 2011, 6770.

[4]. Gondivkar SM, Indurkar A, Degwekar S and Bhowate R, Cheiloscopy for sex determination, Journal of Forensic Dental Sciences, 1(2), 2009, 56-60.

[5]. Hameed $\mathrm{F}$ and Vaswani V, Study of patterns of lip prints and their seasonal variation, J-SIMLA, 8(1), 2016, 11-14

[6]. Vats Y, Dhall JK and Kapoor AK, Gender variation in morphological patterns of lip prints among some north Indian populations, Journal of Forensic Dental Sciences, 4(1), 2012, 19-23. 
[7]. Prabhu RV, Dinkar AD, Prabhu VD and Rao PK, Cheiloscopy: Revisited, Journal of Forensic Dental Sciences, 4(1), 2012 , 47-52.

[8]. Diwivedi N, Agarwal A, Kashyap B, Raj V and Chandra S, Latent lip print development and its role in suspect identification, Journal of Forensic Dental Sciences, 5(1), 2013, 22-27.

[9]. Padmavathi BN, Makkad RS, Rajan SY and Kolli GK, Gender determination using cheiloscopy, Journal of Forensic Dental Sciences, 5(2), 2013, 123-128.

[10]. Sandhu SV, Bansal H, Monga P and Bhandari R, Study of lip print pattern in a Punjabi population, Journal of Forensic Dental Sciences, 4(1), 2012, 24-28.

[11]. Koneru A, Comparison of lip prints in two different populations of India: Reflections based on a preliminary examination, Journal of Forensic Dental Sciences, 5(1), 2013, 11-15.

[12]. Singh J, Gupta KD, Sardana V, Balappanavar AY and Malhotra G, Sex determination using cheiloscopy and mandibular canine index as a tool in Forensic dentistry, J Forensic Dent Sci, 4(2), 2012, 70-74.

[13]. Varghese AJ, Somasekar M and Umesh BR, A study of lip print types among the people of kerala, J Indian Acad Forensic Med, 32, 2010, 6-7.

[14]. Peeran SW et al, A study of lip prints among adults of sebha city, Libya, Journal of Forensic Dental Sciences, 7(1), 2015, 67-70.

[15]. Venkatesh R and David MP, Cheiloscopy: An Aid for personal identification, Journal of Forensic Dental Sciences, 3(2), 2011, 6770.

Table 1: Pattern of Lip Prints described by Suzuki and Tsuchihashi

\begin{tabular}{|l|l|}
\hline Patterns of lip prints & Description \\
\hline Type I & Clear cut groove running vertically across the lip \\
\hline Type I' & Partial length groove of Type I \\
\hline Type II & A branched groove (or) a Y shape pattern \\
\hline Type III & An intersected groove (or) criss cross pattern \\
\hline Type IV & A reticular (or) checkered fence like pattern \\
\hline Type V & Others (or) undetermined pattern \\
\hline
\end{tabular}

Table 2: Overall distribution of Pattern of lip print

\begin{tabular}{|c|c|c|c|c|c|}
\hline Patterns of lip prints & Male & Female & Total & Chi square value & P value \\
\hline Vertical (Type I) & $\begin{array}{l}43 \\
(46.7 \%)\end{array}$ & $\begin{array}{l}37 \\
(34.3 \%) \\
\end{array}$ & $\begin{array}{l}80 \\
(40.0 \%)\end{array}$ & \multirow[t]{6}{*}{10.777} & \multirow[t]{6}{*}{0.027} \\
\hline Branched (Type II) & $\begin{array}{l}26 \\
(28.3 \%)\end{array}$ & $\begin{array}{l}28 \\
(25.9 \%)\end{array}$ & $\begin{array}{l}54 \\
(27.0 \%)\end{array}$ & & \\
\hline Intersected (Type III) & $\begin{array}{l}5 \\
(5.4 \%) \\
\end{array}$ & $\begin{array}{l}3 \\
(2.8 \%) \\
\end{array}$ & $\begin{array}{l}8 \\
(4.0 \%) \\
\end{array}$ & & \\
\hline Reticular (Type IV) & $\begin{array}{l}9 \\
(9.8 \%)\end{array}$ & $\begin{array}{l}29 \\
(26.9 \%)\end{array}$ & $\begin{array}{l}38 \\
(19.0 \%)\end{array}$ & & \\
\hline undermined(Type V) & $\begin{array}{l}9 \\
(9.8 \%)\end{array}$ & $\begin{array}{l}11 \\
(10.2 \%)\end{array}$ & $\begin{array}{l}20 \\
(10.0 \%)\end{array}$ & & \\
\hline Total & $\begin{array}{l}92 \\
(100.0 \%)\end{array}$ & $\begin{array}{l}108 \\
(100.0 \%)\end{array}$ & $\begin{array}{l}200 \\
(100.0 \%)\end{array}$ & & \\
\hline
\end{tabular}

Table 3: Gender wise distribution of upper and lower lip prints

\begin{tabular}{|c|c|c|c|c|c|c|c|}
\hline Lip & Patterns of lip prints & & Male & Female & Total & Fishers exact value & $P$ value \\
\hline \multirow[t]{12}{*}{ Upper lip } & \multirow[t]{2}{*}{ Vertical(Type I) } & Count & 18 & 9 & 27 & \multirow[t]{12}{*}{19.658} & \multirow[t]{12}{*}{0.001} \\
\hline & & Percentage & $39.1 \%$ & $16.7 \%$ & $27.0 \%$ & & \\
\hline & \multirow[t]{2}{*}{ Branched (Type II) } & Count & 21 & 16 & 37 & & \\
\hline & & Percentage & $45.7 \%$ & $29.6 \%$ & $37.0 \%$ & & \\
\hline & \multirow[t]{2}{*}{ Intersected (Type III) } & Count & 1 & 3 & 4 & & \\
\hline & & Percentage & $2.2 \%$ & $5.6 \%$ & $4.0 \%$ & & \\
\hline & \multirow[t]{2}{*}{ Reticular (Type IV) } & Count & 3 & 22 & 25 & & \\
\hline & & Percentage & $6.5 \%$ & $40.7 \%$ & $25.0 \%$ & & \\
\hline & \multirow[t]{2}{*}{ Undermined(Type V) } & Count & 3 & 4 & 7 & & \\
\hline & & Percentage & $6.5 \%$ & $7.4 \%$ & $7.0 \%$ & & \\
\hline & \multirow[t]{2}{*}{ Total } & Count & 46 & 54 & 100 & & \\
\hline & & Percentage & $100.0 \%$ & $100.0 \%$ & $100.0 \%$ & & \\
\hline \multirow[t]{12}{*}{ Lower lip } & \multirow[t]{2}{*}{ Vertical(Type I) } & Count & 25 & 28 & 53 & \multirow[t]{12}{*}{6.311} & \multirow[t]{12}{*}{0.167} \\
\hline & & Percentage & $54.3 \%$ & $51.9 \%$ & $53.0 \%$ & & \\
\hline & \multirow[t]{2}{*}{ Branched (Type II) } & Count & 5 & 12 & 17 & & \\
\hline & & Percentage & $10.9 \%$ & $22.2 \%$ & $17.0 \%$ & & \\
\hline & \multirow[t]{2}{*}{ Intersected (Type III) } & Count & 4 & 0 & 4 & & \\
\hline & & Percentage & $8.7 \%$ & $0.0 \%$ & $4.0 \%$ & & \\
\hline & \multirow[t]{2}{*}{ Reticular (Type IV) } & Count & 6 & 7 & 13 & & \\
\hline & & Percentage & $13.0 \%$ & $13.0 \%$ & $13.0 \%$ & & \\
\hline & \multirow[t]{2}{*}{ Undermined(Type V) } & Count & 6 & 7 & 13 & & \\
\hline & & Percentage & $13.0 \%$ & $13.0 \%$ & $13.0 \%$ & & \\
\hline & \multirow[t]{2}{*}{ Total } & Count & 46 & 54 & 100 & & \\
\hline & & Percentage & $100.0 \%$ & $100.0 \%$ & $100.0 \%$ & & \\
\hline
\end{tabular}


Figure 1: various patterns of Lip prints

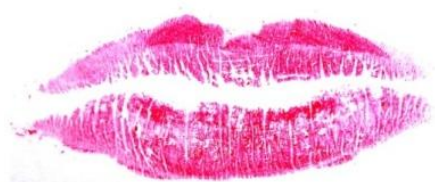

Type I

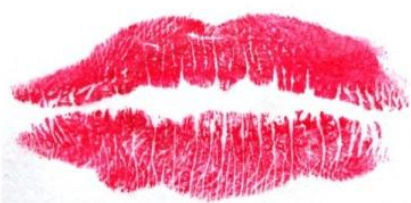

Type II

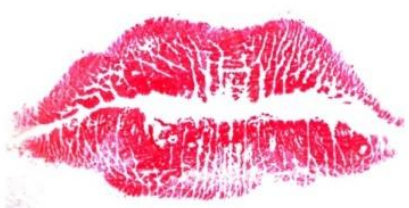

Type IV

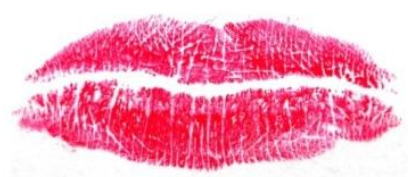

Type I'

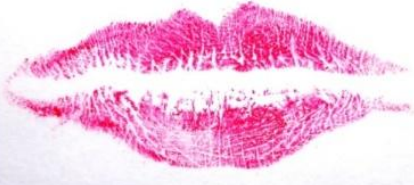

Type III

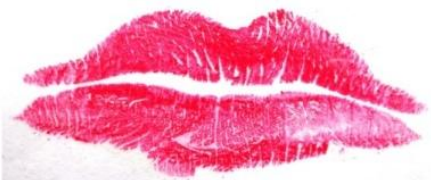

Type V 